\title{
Application of Fuzzy Multi-Objective Linear Programming Model in a Multi-Period Multi- Product Production Planning Problem
}

\author{
Kaveh Taghizadeh \\ Department of Industrial Engineering, Mazandaran University of Science \& Technology, Babol, Iran \\ E-mail: Zehdarkt@Gmail.com \\ Morteza Bagherpour \\ Department of Industrial Engineering, Iran University of science and Technology, Tehran, Iran \\ E-mail: Mortezabagherpour@gmail.com \\ Iraj Mahdavi \\ Department of Industrial Engineering, Mazandaran University of Science \& Technology, Babol, Iran \\ E-mail: Irajarash@rediffmail.com
}

Received: 21-04-2010; Accepted: 14-12-2010

\begin{abstract}
The Multi-Period Multi-Product (MPMP) production planning, as a well known problem in literature, attempts to match production rates of individual products with fluctuated market demand over planning horizon. This study, demonstrates how the conventional MPMP Linear Programming (LP) model may fail to utilize available capacity of machines, and also a novel Multi Objective Linear Programming (MOLP) model is developed to simultaneously minimize net present value of production costs and maximize machine utilization. The proposed model consists of production constraints such as available labor, inventory, maximum subcontracting levels and also forecasted demands. The proposed MOLP model is further converted to a Fuzzy Multi Objective Linear Programming (FMOLP) model utilizing piecewise linear membership functions. The model, accommodates the Decision Maker (DM) with a more systematic decision making approach enabling the DM to adjust the search direction during the solving procedure to achieve the most satisfactory result.
\end{abstract}

Keywords: Multi-Period Multi-Product production planning; Aggregate production planning; Fuzzy Multi-Objective Linear Programming; Piecewise linear membership functions; Mixed Integer Linear Programming;

\section{Introduction}

The standard MPMP problem in production planning environment attempts to determine production rates of individual products in each period and have been increasingly focused by both practitioners and academicians (Hanssmann \& Hess ${ }^{1}$; Bakir \& Byrne $^{2}$; Wang \& Liang $^{3}$; Feylizadeh et $a l^{4}{ }^{4}$ ).

In a competitive market, products' demand may fluctuate significantly due to seasonal/periodical reasons. In such an environment, existence of a reliable and stable production planning system is crucial in order to adjust production rates to available resources and market demand. An appropriate production planning system besides determining the production volumes should also provides the DM with proper strategies of absorbing demand fluctuations. General strategies for absorbing demand fluctuations may be noted as follows ${ }^{5}$ :

i. Variable level of work force results in changing rate of production, although excessive use of hiring and dismissing may be limited by union regulations,

ii. Varying production rates by introduction of outside subcontracting,

iii. Accumulating seasonal inventories, 
iv. Allowing backorder planning.

Any individual or combination of mentioned policies may be used to absorb fluctuations in demand rates. Besides, proper utilization of available machine capacities can substantially affect the quantity of production as well as production costs by reducing backordering and backlogging costs.

In most practical production planning cases, different conflicting objectives may be arisen including minimizing total production costs, inventory investment, changes in production rates, changes in work force levels as well as maximizing profit, customer satisfaction, and utilization of plant and equipments ${ }^{6}$. These conflicting objectives are required to be optimized through a simultaneous analyzing system where DM's judgments regarding priority and importance of each objective can be considered.

Moreover, environmental coefficients and related parameters such as market demand and available resources are normally assigned by experts. In most real situations, experts have an imprecise or ambiguous insight of such parameters. Thus, it would be more appropriate to represent these parameters using fuzzy numbers.

This work represents a novel multi objective mathematical model for solving the MPMP production planning problem where operational sequence of individual products has been also considered. We discuss, although considering production routes may show a significant impact on utilization of machines available capacities, this issue hasn't been previously taken into consideration in the conventional MPMP models. The original MOLP model attempts to simultaneously minimize net present value of total production, carrying and backordering costs, rate of changes in labor levels, and maximizes machine utilization subject to available inventory capacity, resource levels. Furthermore, the proposed model is converted into an FMOLP model, where piecewise linear membership functions are introduced to indicate the satisfaction degree of DM from different values of objective functions. Moreover, triangular fuzzy numbers are utilized to deal with imprecision of DM's judgments about market demand and available machine capacity.

The remainder of this work is organized as follows: Section 2 reviews the literature for related topics. Section 3 describes fallaciousness of the conventional MPMP formulations in utilizing available machine capacities and how considering production routes can affect production capacity and costs. Section 4 presents the model formulation and provides a method to convert FMOLP formulation to a simple single objective linear model. Additionally, Sec.5 suggests an interactive procedure to embed the DM's judgments in planning process. Section 6 includes a numerical example, sensitivity and comparative analyses. Finally, conclusions are drawn in Sec.7.

\section{Literature Review}

Since this research applies both Aggregate Production Planning (APP) and MPMP notions as an integrated model, a comprehensive review of both mentioned topics is presented below.

The conventional LP formulation of the MPMP problem focuses on matching production rates of multi products with fluctuated market demand over planning horizon. The standard form of the MPMP model, (see Refs. 7 and 8 for more details) considers minimizing total production related costs including variable production, inventory, and shortages costs as objective function.

Bakir \& Byrne ${ }^{2}$ pointed out uncertainties in discrete manufacturing systems can affect the feasibility of solution to a large extent, and developed a stochastic linear programming model dealing with uncertain demands. Later, Byrne \& Bakir $^{9}$ presented a hybrid simulation-analytical approach to cope with complex behavior of resource consumption in a real-world manufacturing system. Then, Kim \& $\mathrm{Kim}^{10}$ identified the actual work load of jobs and utilization of resources in each simulation run and passed the information to the linear programming model in order to provide the optimal production plan with minimum total costs. They also compared their approach with Byrne \& Bakir $^{9}$ approach and showed that their approach takes less iteration to find a better solution. Byrne \& Hossain ${ }^{11}$ extended models proposed by Byrne \& Bakir ${ }^{9}$ and Kim $\& \mathrm{Kim}^{10}$, considering unit load notion of a Just In Time (JIT) production system. They attempted to improve the planning model by reducing the level of semi-products and total flow time.

Brandimarte $^{12}$ proposed a multi-stage stochastic programming approach for multi-item capacitated lot sizing problem, considering uncertain demand. Noori et $a l{ }^{13}$ discussed, machine utilization in the MPMP production planning problem can be improved by 
converting the problem into a project scheduling problem and assigning resources to activities and consequently leveling the resource profiles. Concurrently, Feylizadeh et $a{ }^{4}{ }^{4}$ developed an approach incorporating cost-time trade off models in MPMP production problem. They attempted to crash total completion time by applying three objectives including minimization of total cost and total time as well as maximization of quality levels. Bagherpour et $a l .{ }^{14}$ implemented the earned value analysis as a project control mechanism, through an MPMP production problem. They modeled the uncertainty associated with activities durations using triangular fuzzy numbers and utilized forecasting features of earned value analysis method to predict completion time of individual products.

Kazemi Zanjani et al. ${ }^{15}$ also developed a multi-stage stochastic programming model to solve the MPMP production problem in presence of uncertainty in the quality of raw material and consequently in processes yields, and uncertainties in products demand. Kazemi Zanjani et $a l .{ }^{16}$ highlighted the superiority of robust optimization compared with stochastic programming in uncertain environment by applying robust optimization approach to determine production plans with robust customer service level.

Many researchers have combined notions of the MPMP problem with features of the APP production planning problems. In this respect, they developed more reliable mathematical formulation that not only indicates optimized production rates but also adopts policies regarding issues such as hiring, dismissing, planning backorder, subcontracting and inventory (Lai \& Hwang $^{17}$; Shi \& Haase $^{18}$; Wang \& Liang ${ }^{19}$ ).

Fuzzy sets theory is a type of imprecision which has no well-defined boundaries for its description. ${ }^{20}$ Fuzzy sets theory is highly applicable in the problems involving human judgments, evaluations, and decisions. ${ }^{21}$ Inclusion of fuzzy sets theory in optimization problems results in reduction of information costs and circumvention of unrealistic modeling. ${ }^{22}$

Zimmermann $^{23}$ first applied fuzzy set theory into conventional LP problems by considering fuzzy objectives and fuzzy constraints. Then, proposed an approach using fuzzy min-operator to transform FMOLP models into single objective LP models. ${ }^{24}$ Rinks $^{25}$ utilized fuzzy linguistic relational assignment rules for APP production planning problems. Nakamura ${ }^{26}$ proposed an approach to solve FMOLP models with quasiconcave membership functions. Nakamura's approach divides the original problem into $2^{\sum_{-l}^{n} v_{i}}$ subproblems, where $v_{i}$ represents the number of intersections between concave functions and convex functions. Zimmermann $^{27}$ introduced an approach based on Fuzzy Linear Programming (FLP) and approximate reasoning to solve APP scheduling problems in flexible manufacturing systems. Yang et $a .^{28}$ developed an approach to solve quasiconcave FMOLP models using $\sum_{i=1}^{n} v_{i}$ additional zero-one variables. Gen et $a .^{29}$ attempted to solve APP problems with fuzzy parameters through an interactive solving procedure. Wang and Fang $^{30}$ proposed a model to minimize total quadratic costs of production and linear inventory costs, considering fuzzy demands and capacities. $\mathrm{Li}$ and $\mathrm{Yu}^{31}$ proposed a method for solving FMOLP problems with quasiconcave membership functions and fuzzy coefficients. Their method, first represents a piecewise linear membership function as the summation of absolute terms and then, searches for the interval where the optimal solution is allocated.

Wang and Liang ${ }^{32}$ suggested a novel interactive FMOLP model to minimize total production costs, carrying and backordering costs and costs of changes in labor levels. Fengjie et $a l .{ }^{33}$ provided an approximate algorithm for solving FMOLP problems considering fuzzy parameters in any form of membership functions in both objective functions and constrains. Jamalnia and Soukhakian ${ }^{34}$ proposed an FMOLP model with different goal priorities using linguistic variables and trapezoidal fuzzy numbers. Additional references regarding FMOLP models and production planning problems include Refs. 35-38.

Liang and Cheng ${ }^{39}$ utilized piecewise linear membership functions and fuzzy min operator to optimize a multi objective production and distribution planning problem. Liang $^{40}$ applied FMOLP models in production and distribution planning decisions using linear membership functions.

This study addresses production planning of multiple products over multi period planning horizon, where aspiration levels of objectives and parameters are not precisely known and depend on expert judgments. Piecewise linear membership functions are utilized to deal with fuzzy conflicting objectives. Triangular fuzzy numbers are utilized to deal with imprecision of environmental parameters, which is mainly due to incomplete or unobtainable information. 


\section{Importance of Considering Production Route in the MPMP Production Planning}

The traditional MPMP model conventionally ignores production route of individual products. The classical MPMP model, normally, considers equal production rates for each process or it is assumed process routes of all products to be the same. In this section, we will discuss how the traditional MPMP model may fail to utilize the potential available capacity of machines.

$\sum_{n=1}^{N} M_{n j t} \cdot Q_{n t} \leq M C_{j t} \quad \forall j, t$

Eq. (1) represents the typical machine capacity constraint of the conventional MPMP model (see Refs. 2, 3, 16, and 34 for more details) in which $M_{n j t}$ represents processing time of $n t h$ product on $j t h$ machine in period $t, Q_{n t}$ indicates total production volume of $n t h$ product in period $t$, and $M C_{j t}$ is the maximum available capacity of $j$ th machine center in period $t$.

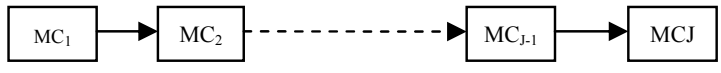

Fig. 1. Single-Product production system

Now, Considering Fig. 1 which depicts a single-product production system, according to Eq. (1) the optimal production rate is equal to $Q^{*}=\operatorname{Min}\left\{M C_{l} / M_{l}, \ldots, M C_{j} / M_{j}, \ldots, M C_{J} / M_{J}\right\}$, in which $M C_{j}$ is the total available capacity of $j$ th machine center and $M_{j}$ is the processing time on $j$ th machine. Thus, conventional MPMP formulation considers the system's production capacity to be equal to minimum production capacity of all machine centers; however in a multi period production system the extra available machine capacities can be utilized to produce semi-products.

Similarly, in a multi-product production system (Fig. 2) total production unit of a part on each machine center is equal to $Q_{n}{ }^{*}=\operatorname{Min}\left\{M C_{n 1}{ }^{*} / M_{n 1}, \ldots, M C_{n j}{ }^{*} / M_{n j}, \ldots, M C_{n J}^{*} / M_{n J}\right\}$, in which $M C^{*}{ }_{n j}$ is the available capacity of $j t h$ machine to produce $n t h$ product in period $t$.
Thus, the standard MPMP mathematical model may circumscribe the feasible region. In other words, utilization of extra production capacity to produce semiproducts has not been previously taken into consideration in the conventional MPMP models, however, by considering production route of individual products, production of semi-products can be planned and it would be possible to lower backordering and backlogging levels.

\section{Mathematical Formulation}

The original MOLP model proposed in this paper deals with minimizing net present value of production related costs and maximizing machine utilization simultaneously. Production related costs include production, inventory, shortage, subcontracting costs and those associated with hiring/dismissing man-hour. Here, the two objective functions are fuzzy and piecewise linear membership functions are introduced to denote the DM's satisfaction degrees with obtained objective values. The minimum operator of $\operatorname{Hannan}^{41}$ and Zimmermann $^{24}$ is utilized, to aggregate all fuzzy sets. Moreover, because of simplicity and flexibility of fuzzy triangular arithmetic operations, computational efficiency as well as facilitate data acquisition triangular fuzzy numbers are utilized to deal with uncertainty associated with market demand and available machine capacity. ${ }^{42}$ Following notations are used in the proposed model:

- Index sets

$\begin{array}{ll}n & \text { index for product, } n=1,2, \ldots, N \\ i & \text { index for process, } i=1,2, \ldots, P_{n} \\ t, k & \text { index for planning time period, } t \text { and } k=1,2, \ldots, T \\ j & \text { index for machine center, } j=1,2, \ldots, J \\ g & \text { index for objective, } g=1,2, \ldots, G . \\ & \\ \text { - } & \text { Objective functions } \\ Z_{1} & \text { Total Costs (\$) } \\ Z_{2} & \text { Total machine Utilization }\end{array}$

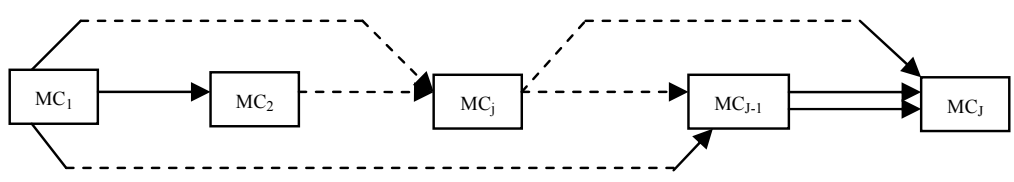

Fig. 2. Multi-Product production system 


\section{- Parameter definition}

\begin{tabular}{|c|c|}
\hline$D_{n k}$ & $\begin{array}{l}\text { forecasted demand for } n \text {th product in period } \\
k \text { (unit) }\end{array}$ \\
\hline$C_{n i}$ & $\begin{array}{l}\text { operation cost of } i \text { th process of } n \text {th product } \\
\text { in first period (\$/unit) }\end{array}$ \\
\hline$e_{c}$ & $\begin{array}{l}\text { escalation factor for regular production cost } \\
(\%)\end{array}$ \\
\hline$M c_{j t}$ & $\begin{array}{l}\text { maximum capacity of machine center } j \text { in } \\
\text { period } t \text { (machine-hour) }\end{array}$ \\
\hline$C s_{n i}$ & $\begin{array}{l}\text { inventory carrying cost per unit of } n \text {th } \\
\text { product which has completed its } i \text { th process } \\
\text { in first period (\$/unit) }\end{array}$ \\
\hline$e_{s}$ & $\begin{array}{l}\text { escalation factor for inventory carrying cost } \\
(\%)\end{array}$ \\
\hline$C b_{n}$ & $\begin{array}{l}\text { backorder cost for unit of } n \text {th product in } \\
\text { first period (\$/unit) }\end{array}$ \\
\hline$e_{b}$ & $\begin{array}{l}\text { escalation factor for planning backorder } \\
\text { cost }(\%)\end{array}$ \\
\hline$C s u_{r}$ & subcontracting cost of $i$ th process of $n$th \\
\hline
\end{tabular}

- Decision variables

$Q_{\text {nitt }} \quad$ The total production volume of the $i$ th process of $n$th product in period $t$ (unit)

The quantity of $n$th product which has completed its $i$ th process in period $t$ and will be stored to be used in period $k$ where $k>t$ (unit)

The quantity of backordered demand of product $n$ in period $t$ that will be fulfilled in period $k$ where $k<t$ (unit)

subcontracted volume for $i$ th process of $n$th product in period $t$ (unit)

$H_{t} \quad$ workers hired in period $t$ (man-hour)

$F_{t} \quad$ workers laid off in period $t$ (man-hour)

$B C_{n t} \quad$ binary variable to indicate whether demand of finished product of type $n$ in period $t$ is backordered or not

binary variable to indicate whether inventory of finished product of type $n$ in period $t$ is planned or not

The decision variable $Q$ involves two indices of time periods. In this regard, the first index indicates production period and second one represents the period of usage. For instance, $Q_{\text {nitt }}$ represents production volume of $i$ th process of part type $n, Q_{\text {nitk }}$ represents inventory levels of semi-products of type $n$ in period $t$ to be used in period $k$ (where $t<k$ ), and $Q_{n, P n, t k}$ indicates the quantity of demand of finished products of type $n$ which have been backordered in period $t$ to be fulfilled in period $k$ (where $t>k$ ).

\subsection{Fuzzy multi-objective linear programming model}

\subsubsection{Objective functions}

As earlier pointed out, this study develops multiple objectives for solving the MPMP production planning problem. Several objectives for the MPMP problem have been reported in literature including minimizing total cost/ maximizing total profit, minimizing variations in material and labor levels (quantitative objectives), and maximizing customer satisfaction (qualitative objective) (see Refs. 2,3, and 34 for more details). However, maximizing machine utilization has not been taken into account in any of existing research. Here, machine utilization is formulated as an additional objective due to its significant impact on subcontracting, backordering, 
backlogging levels, and associated costs as well as indirect costs regarding to idle time of machines.

- Minimize total costs

$$
\begin{aligned}
\min z_{l} \cong & \sum_{n=1}^{N} \sum_{i=1}^{P_{n}} \sum_{t=1}^{T} Q_{n i t t} \times C_{n i} \times\left(1+e_{c}\right)^{t}+ \\
& \sum_{n=1}^{N} \sum_{i=1}^{P_{n}} \sum_{t=1}^{T} \sum_{k>t}^{T}(k-t) \times Q_{n i t k} \times C s_{n i} \times\left(1+e_{s}\right)^{t}+ \\
& \sum_{n=1}^{N} \sum_{k=1}^{T} \sum_{t>k}(t-k) \times Q_{n P_{n} t k} \times C b_{n} \times\left(1+e_{b}\right)^{t}+ \\
& \sum_{n=1}^{N} \sum_{i=1}^{P_{n}} \sum_{t=1}^{T} S u_{n i t} \times C s u_{n i} \times\left(1+e_{s u}\right)^{t}+ \\
& \sum_{t=1}^{T}\left(H_{t} \times C h \times\left(1+e_{h}\right)^{t}+F_{t} \times C f \times\left(1+e_{f}\right)^{t}\right) .
\end{aligned}
$$

\section{- Maximize total machine utilization}

$$
\max z_{2} \cong \frac{\sum_{n=1}^{N} \sum_{i=1}^{P_{n}} \sum_{t=1}^{T} \sum_{j=1}^{J}\left(Q_{n i t t} \times M_{i j n}\right)}{\sum_{j=1}^{J} \sum_{t=1}^{T} M c_{j t}}
$$

The symbol ' $\cong$ ' is expressing equivalency under fuzzy conditions and refers to the fuzzification of the aspiration levels. In real-world MPMP applications, Eq. (2) and (3) are often involved with variations in DM's judgment, thus piecewise linear membership functions are introduced to embed DM's judgments about different values of objective functions within planning process. The impact of time value of money also is considered on each cost category, in this regard, the time value of money in each period is compared with first period.

The first term of Eq. (2) represents production related costs which may encompass machine costs, raw material, etc. Inventory carrying costs represented by the second term, involves holding periods of both semi-products and finished products. Backlogging costs as the third term, takes into account the interval time between demand and fulfillment (shortage periods). Finally, the fourth and fifth terms represent the cost associated with subcontracting and hiring/dismissing workforce, respectively.

Eq. (3) attempts to maximize total machine utilization, in this regard total production time of machines is divided with total available capacity of machines.

\subsubsection{Constraints}

- Machine center capacity constraints

$\sum_{n=1}^{N} \sum_{i=1}^{P_{n}} Q_{n i t t} \times M_{i j n} \leq \tilde{M} c_{j t} \quad \forall t, \forall j$.

Eq. (4) ensures total utilization of each machine center in each period (left hand side) does not exceed the total available capacity of machine center (right hand side), which in most practical cases is often fuzzy/imprecise. The proposed machine capacity constraint utilizes required quantity of process on each machine in each period $\left(Q_{\text {nitt }}\right)$ to calculate processing time of each machine, despite, the conventional constraint focuses on required volume of finished products $\left(Q_{n t}\right)$ to be produced in each period. The number of required processes to be undertaken is mainly determined based on material balance constraints.

- Material balance constraints

$$
\begin{aligned}
& Q_{n i k k}+S u_{n i k}= \\
& \sum_{t \leq k} Q_{n, i-1, t k}-\sum_{t>k} Q_{n, i-1, k t}+S u_{n, i-1, k} \quad \forall i \geq 2, \forall n, \forall k . \\
& \sum_{t \leq k} Q_{n P_{n} t k}+\sum_{t>k}^{T} Q_{n P_{n} t k}-\sum_{t>k}^{T} Q_{n P_{n} k t}+S u_{n P_{n} k}= \\
& \tilde{D}_{n k}+\sum_{t<k} Q_{n P_{n} k t} \quad \forall n, \forall k .
\end{aligned}
$$

In a production system, generally, material flow at each period should be balanced from two points of views: (1) inventory/shortage and subcontracting levels should be equal to those from previous periods, production quantity, and demand. (2) The total number of parts at each process is restricted to the total number of available parts which have completed the previous processes beforehand. In this respect, Eq. (5) is proposed here to make sure that total number of produced and subcontracted parts in each process does not exceed the total production and inventory of the previous process (denoted by the first term in the right hand side), and the number of parts stored for future periods (given by the second term in the right hand side), plus the subcontracted parts of the previous process (given by the third term in the right hand side).

Similar explanation can be made for Eq. (6), where the total produced and subcontracted parts and inventory of the finished parts should be equal to the forecasted demand of each product and inventory level for future periods. The market demand in right hand side of Eq. (5) 
is often fuzzy/ imprecise due to the uncertainty of demand, and supply of competitors in market.

$\sum_{t>k} Q_{n P_{n} t k} \times \sum_{t>k} Q_{n P_{n} k t}=0 \quad \forall n, \forall k$.

Eq. (7), developed in this model, to prevent concurrent planning of holding inventories and backorders.

- Maximum inventory space constraints

$\sum_{n=1}^{N} \sum_{t \leq k} \sum_{k^{\prime}>k} Q_{n i t k^{\prime}} \times P i_{n i} \leq \operatorname{Imax}_{k} \quad \forall i=P_{n}, \forall k$

$\sum_{n=1}^{N} \sum_{i=1}^{P_{n}-1} \sum_{t \leq k} \sum_{k^{\prime}>k} Q_{n i t k^{\prime}} \times P i_{n i} \leq W I P \max _{k} \quad \forall k$.

In this study production and storage of semi-products are considered to represent features of real world cases. Constraints (8) and (9) are formulated to assure that total inventory of finished and semi-products would not exceed the maximum available space of finished and semi-product warehouses.

\section{- Workforce constraints}

$\sum_{n=1}^{N} \sum_{i=1}^{P_{n}} Q_{n i t t} \times P m_{n i} \leq \operatorname{Wmax}_{t} \quad \forall t$

$\sum_{n=1}^{N} \sum_{i=1}^{P_{n}} Q_{n i t t} \times P m_{n i}=$

$\sum_{n=1}^{N} \sum_{i=1}^{P_{n}} Q_{n i, t-1, t-1} \times P m_{n i}+H_{t}-F_{t} \quad \forall t$.

Eq. (10) ensures that the maximum available workforce will not be exceeded and Eq. (11) balances the labor levels between periods.

\section{- Subcontracting constraints}

$$
\sum_{n=1}^{N} \sum_{i=1}^{P_{n}} S u_{n i t} \leq \operatorname{Smax}_{t} \quad \forall t .
$$

Due to managerial policies of subcontracting, Eq. (12) makes sure that total number of subcontracted items in each period would not exceed the allowed level.

\section{- Linearization}

The proposed Fuzzy Multi Objective Nonlinear Programming (FMONLP) formulation encompasses Eq. (2) through (12). However, the FMONLP model can be converted to an FMOLP model by introducing following equations:

$$
\begin{array}{ll}
R \times B c_{n k} \geq \sum_{t>k}^{T} Q_{n P_{n} t k} & \forall n, \forall k \\
R \times I n_{n k} \geq \sum_{t>k}^{T} Q_{n P_{n} k t} & \forall n, \forall k \\
B c_{n k}+I n_{n k} \leq 1 & \forall n, \forall k .
\end{array}
$$

Finally, by replacing Eq. (13-15) instead of Eq. (6) the proposed FMONLP model is converted to an FMOLP. In this regard, $\mathrm{R}$ in Eq. (13) and (14) represents a large positive number and Eq. (15) eliminates simultaneous occurrence of carrying inventory and planning backorder.

\section{Solution Strategy}

\subsection{Treatment of the fuzzy constraints}

Here, triangular fuzzy numbers are adopted to cope with fuzziness/uncertainty of market demand and machine capacity. The main advantage of adopting triangular fuzzy numbers is ease of defining, simplicity and flexibility of fuzzy arithmetic operations, and simplistic data acquisition. ${ }^{16}$ and 43 In practice, the DM is almost familiar with defining the maximum negative and positive deviations of fuzzy numbers from their central value. Rommelfanger ${ }^{44}$ recommended utilizing triangular distribution, when knowledge of the distribution is limited.

Practically, the triangular distribution can easily be constructed based on three prominent values (Fig. 3):

i. The most likely value that definitely belongs to the set of available values (membership degree $=1$ if normalized).

ii. The minimum accepted value in the range of available values which has a very low probability of occurrence (membership degree $=0$ if normalized)

iii. The maximum accepted value in the range of available values which has a very low probability of occurrence (membership degree= 0 if normalized).

In this study, the weighted average method is utilized to convert fuzzy variables into crisp numbers. ${ }^{27}$, and 32 By introducing the minimum accepted membership degree $\alpha$ 
for triangular fuzzy numbers, Eq. (3) and (5) can be represented as follows:

$$
\begin{aligned}
& \sum_{n=1}^{N} \sum_{i=1}^{P_{n}} Q_{n i t t} \times M_{i j n} \leq \\
& w_{1} M c_{j t, \alpha}^{P}+w_{2} M c_{j t, \alpha}^{m}+w_{3} M c_{j t, \alpha .}^{o} \quad \forall t, \forall j \\
& \sum_{t \leq k} Q_{n P_{n} t k}+\sum_{t>k}^{T} Q_{n P_{n} t k}-\sum_{t>k}^{T} Q_{n P_{n} k t}+S u_{n P_{n} k}= \\
& w_{l} D_{n k, \alpha}^{p}+w_{2} D_{n k, \alpha}^{m}+w_{3} D_{n k, \alpha}^{o}+\sum_{t<k} Q_{n P_{n} k t} \quad \forall n, \forall k .
\end{aligned}
$$

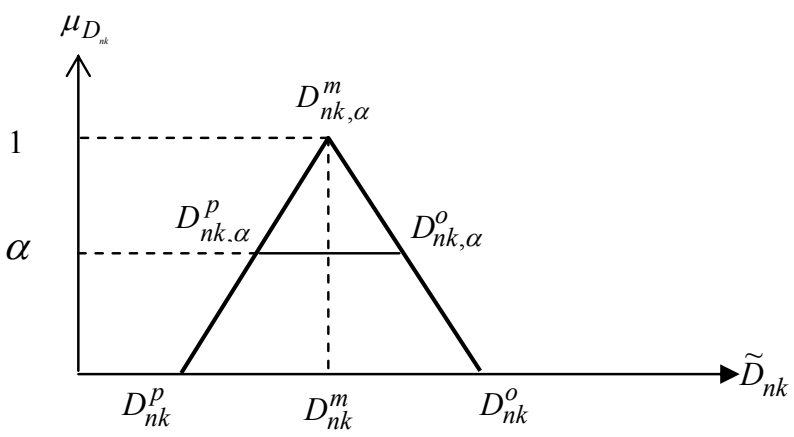

Fig. 3. The distribution of triangular fuzzv number

\subsection{Solving the fuzzy multi-objective linear programming problem}

Both fuzzy decision making concept introduced by Bellman and Zadeh $^{52}$ and fuzzy goal programming method presented by Hannan ${ }^{41}$ have been utilized to solve proposed FMOLP model. In this respect, piecewise linear membership functions are adopted to represent all fuzzy objectives and the minimum operator is used to aggregate all fuzzy sets. Then, the auxiliary variable $\mu$ is introduced to convert the original model to a standard LP model which can be solved efficiently by simplex method. The auxiliary variable $\mu$ specifies the overall satisfaction degree of DM with objective values. Fallowing steps demonstrate the procedure of converting the FMOL model to an LP model. ${ }^{3}$

Step1. Specify the degree of membership $f_{g}\left(z_{g}\right)$ for several values for each of the objective functions $\mathrm{z}_{g}, g=1,2, \ldots, G$. (Table 1)
Table 1. Membership function of $f_{i}\left(z_{i}\right)$

\begin{tabular}{llllllll}
\hline$z_{1}$ & $>\mathrm{X}_{10}$ & $\mathrm{X}_{10}$ & $\mathrm{X}_{11}$ & $\ldots$ & $\mathrm{X}_{1 \mathrm{~b}}$ & $\mathrm{X}_{1 \mathrm{~b}+1}$ & $<\mathrm{X}_{1 \mathrm{~b}+1}$ \\
$F_{1}\left(z_{1}\right)$ & 0 & 0 & $\mathrm{q}_{11}$ & $\ldots$ & $\mathrm{q}_{1 \mathrm{~b}}$ & $\mathrm{q}_{1 \mathrm{~b}+1}$ & $\mathrm{q}_{1 \mathrm{~b}+1}$ \\
$Z_{2}$ & $>\mathrm{X}_{20}$ & $\mathrm{X}_{20}$ & $\mathrm{X}_{21}$ & $\ldots$ & $\mathrm{X}_{2 \mathrm{~b}}$ & $\mathrm{X}_{2 \mathrm{~b}+1}$ & $<\mathrm{X}_{2 \mathrm{~b}+1}$ \\
$F_{2}\left(z_{2}\right)$ & 0 & 0 & $\mathrm{q}_{21}$ & $\ldots$ & $\mathrm{q}_{2 \mathrm{~b}}$ & $\mathrm{q}_{2 \mathrm{~b}+1}$ & $\mathrm{q}_{2 \mathrm{~b}+1}$ \\
\hline
\end{tabular}

Note: $0 \leq q_{m n} \leq 1, q_{m n} \leq q_{m n+l} m=1,2 \quad n=1,2, \ldots, b$.

Step2. Draw the piecewise linear membership functions for each objective based on data acquired in the first step.

Step3. Assume $f_{g}\left(z_{g}\right)=t_{g r} z_{g}+S_{g r}$ to be linear function of each objectives segment $X_{g, r-1} \leq z_{g} \leq X_{g r}$, in which $t_{g r}$, and $S_{g r}$ are the slope and $\mathrm{y}$-intercept of linear section between $X_{g, r-1}$, and $X_{g, r}$.

Step4. Calculate $\alpha_{g e}=\left|t_{g, e+1}-t_{g e} / 2\right|$,

$\beta_{g}=\left(t_{g, b_{g}+1}+t_{g 1}\right) / 2, \gamma_{g}=\left(S_{g, b_{g}+1}+S_{g 1}\right) / 2$

and convert the membership functions $f_{g}\left(z_{g}\right)$ into the following form:

$f_{g}\left(z_{g}\right)=\sum_{e=1}^{b_{g}} \alpha_{g e}\left|z_{g}-X_{g e}\right|+\beta_{g} z_{g}+\gamma_{g} \quad g=1,2, \ldots, G$.

Expanding Eq. (18), Eq. (19) would be formulated as follows:

$$
\begin{aligned}
f_{g}\left(z_{g}\right)= & -\left(\frac{t_{g 2}-t_{g 1}}{2}\right)\left|z_{g}-X_{g}\right|- \\
& \left(\frac{t_{g 3}-t_{g 2}}{2}\right)\left|z_{g}-X_{g 2}\right|-\ldots- \\
& \left(\frac{t_{g, b_{g}+1}-t_{g P_{g}}}{2}\right)\left|z_{g}-X_{g b_{g}}\right|+\left(\frac{t_{g, b_{g}+1}+t_{g 1}}{2}\right) z_{g}+ \\
& \frac{S_{g, b_{g}+1}+S_{g 1}}{2} \quad g=1,2, \ldots, G . \quad e=1,2, \ldots, b_{g} .
\end{aligned}
$$

Where $b_{g}$ is the number of breakpoints of $g$ th objective function.

Step5. Introduce the non-negative divisional variables.

$z_{g}+d_{g e}^{-}-d_{g e}^{+}=X_{g e} g=1,2, \ldots, G, e=1,2, \ldots, b_{g}$.

Now Eq. (21) can easily formulated by substituting $\left(z_{g}-X_{g e}\right)$ from Eq. (20) in Eq. (19). 


$$
\begin{aligned}
f_{g}\left(z_{g}\right)=-\left(\frac{t_{g 2}-t_{g 1}}{2}\right)\left(d_{g 1}^{-}+d_{g 1}^{+}\right)- \\
\left(\frac{t_{g 3}-t_{g 2}}{2}\right)\left(d_{g 2}^{-}+d_{g 2}^{+}\right)-\ldots- \\
\left(\frac{t_{g, b_{g}+1}-t_{g b_{g}}}{2}\right)\left(d_{g b_{g}}^{-}+d_{g b_{g}}^{+}\right)+ \\
\left(\frac{t_{g, b_{g}+1}+t_{g 1}}{2}\right) z_{g}+ \\
\quad \frac{S_{g, b_{g}+1}+S_{g 1}}{2} g=1,2, \ldots, G, e=1,2, \ldots, b_{g} .
\end{aligned}
$$

Step 6. By introducing the auxiliary variable $\mu$ $(0 \leq \mu \leq 1)$, as a minimum operator to aggregate fuzzy sets, the proposed FMOLP model can be converted to ordinary single objective LP model.

$$
\begin{aligned}
& \operatorname{Max} \mu \\
& \text { s.t. } \mu \leq-\left(\frac{t_{g 2}-t_{g I}}{2}\right)\left(d_{g 1}^{-}+d_{g l}^{+}\right)- \\
& \left(\frac{t_{g 3}-t_{g 2}}{2}\right)\left(d_{g 2}^{-}+d_{g 2}^{+}\right)-\ldots-\left(\frac{t_{g, b_{g}+1}+t_{g b_{g}}}{2}\right) \times \\
& \left(d_{g b_{g}}^{-}+d_{g b_{g}}^{+}\right)+\left(\frac{t_{g, b_{g}+1}+t_{g l}}{2}\right) z_{g}+\frac{S_{g, b_{g}+1}+S_{g l}}{2}, \forall g \\
& z_{g}+d_{d e}^{-}-d_{g e}^{+}=X_{g e} \quad \forall g, e \\
& \text { Eqs. (4),(5),(8-15), 16,17 } \\
& Q_{\text {nitt }}, Q_{\text {int }}, S u_{\text {nit }}, H_{t}, F_{t} \geq 0
\end{aligned}
$$

\subsection{Solution procedure}

Here, an interactive decision making procedure is presented in which the DM can adjust the search direction through each run until satisfactory results are obtained. In Fig. 4, the procedure of solving the FMOLP model is presented.

\section{An illustrative example}

\subsection{Data description}

In order to implement the proposed FMOLP model, a production system including three products is generated. The system encompasses five machine centers and each product goes through four machine centers according to its own production sequence. Fig. 5 depicts operational sequence including machine processing time for each product. Tables (2-4) summarize problem parameters, in which Table (1) include production related data, and Tables $(2,3)$ encompass information about market demand over a three-week planning horizon and available machine capacity respectively which are presented using triangular fuzzy numbers.

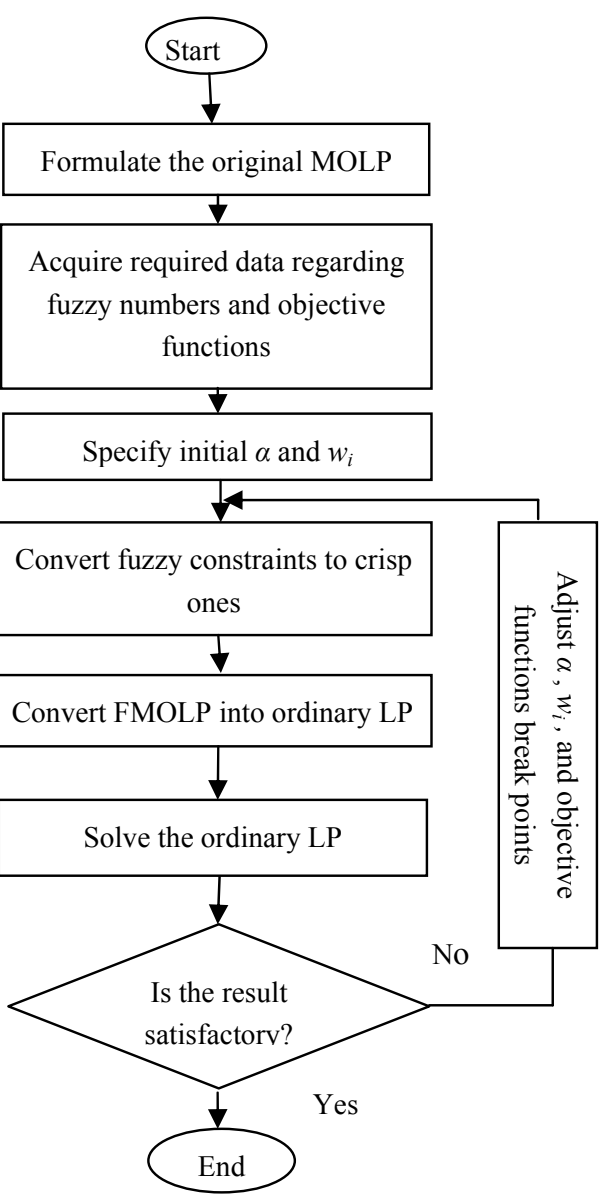

Fig. 4. Interactive procedure of solving FMOLP 


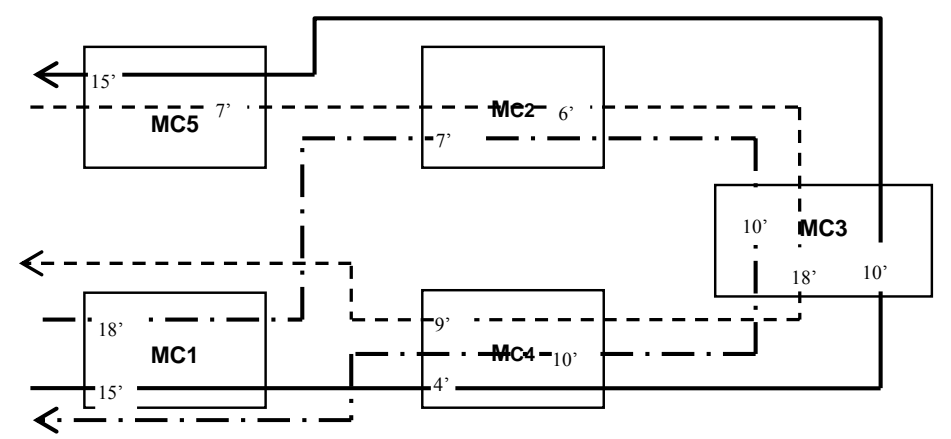

Product 1

Product 2 - - - -

Product $3-\cdot-$

Fig. 5. Machine order visit

Table 2. Production data

\begin{tabular}{cccccccc}
\hline Product & Process & $\boldsymbol{C}_{\boldsymbol{n} \boldsymbol{i}}$ & $\boldsymbol{C s}_{\boldsymbol{n i}}$ & $\boldsymbol{C s u}_{\boldsymbol{n}}$ & $\boldsymbol{P m}_{\boldsymbol{n i}}$ & $\boldsymbol{P i}_{\boldsymbol{n i}}$ & $\boldsymbol{C b}_{\boldsymbol{n}}$ \\
\hline 1 & 1 & 100 & 145 & 180 & 1.0 & 1.5 & \\
& 2 & 120 & 235 & 185 & 0.7 & 1.6 & \\
& 3 & 125 & 255 & 400 & 0.8 & 1.7 & \\
& 4 & 135 & 265 & 500 & 1.0 & 1.9 & 45 \\
& 1 & 150 & 115 & 130 & 1.0 & 1.8 & \\
& 2 & 150 & 235 & 200 & 0.7 & 2.0 & \\
& 3 & 150 & 255 & 185 & 0.8 & 2.4 & \\
& 4 & 165 & 265 & 200 & 1.0 & 2.5 & 65 \\
& 1 & 145 & 115 & 165 & 1.0 & 1.7 & \\
& 2 & 150 & 235 & 175 & 0.7 & 1.9 & \\
& 3 & 150 & 255 & 400 & 0.8 & 2.0 & \\
& 4 & 140 & 265 & 500 & 1.0 & 2.5 & 75 \\
\hline
\end{tabular}

Table 3. Fuzzy market demand data

\begin{tabular}{llll}
\hline \multirow{2}{*}{ Period } & & \\
& $\mathbf{2}$ & $\mathbf{3}$ \\
\hline 1 & $(85,106,115)$ & $(95,11,115)$ & $(150,164,190)$ \\
2 & $(105,119,145)$ & $(85,90,95)$ & $(120,152,160)$ \\
3 & $(100,104,120)$ & $(75,90,105)$ & $(115,146,160)$ \\
\hline
\end{tabular}

Other complementary information is given as follows:

i. Escalation factors assumed to be equal to zero.

ii. The initial available labor level in period 1 is equal to 1000 and maximum level of workforce in each period is announced by production manager equal to 2000 .

iii. Costs associated with hiring and dismissing man-hour are equal to 20 and 30 (\$/man-hour) respectively.
Table 4. Fuzzy machine capacity data

\begin{tabular}{llll}
\hline ว & Period & & \\
& $\mathbf{1}$ & $\mathbf{2}$ & $\mathbf{3}$ \\
\hline 1 & $(2100,2520,2700)$ & $(2100,2520,2700)$ & $(2100,2520,2700)$ \\
2 & $(2150,2510,2750)$ & $(2150,2510,2750)$ & $(2150,2510,2750)$ \\
3 & $(1860,1991,2230)$ & $(1860,1991,2230)$ & $(1860,1991,2230)$ \\
4 & $(2750,3015,3100)$ & $(2750,3015,3100)$ & $(2750,3015,3100)$ \\
5 & $(2200,2410,2500)$ & $(2200,2400,2500)$ & $(2200,2410,2500)$ \\
\hline
\end{tabular}

iv. There is no initial inventory available in period 1 ; however production system requires 0,5 , and 10 units of end inventory for products 1,2 , and 3 respectively in the last period.

v. The available space of finished product's warehouse and work-in-process warehouse are equal to 200 and $100 \mathrm{ft}^{2}$.

vi. Based on subcontracting strategy plan, the maximum allowable number of subcontracting items in each period is equal to 400 units.

\subsection{Model implementation and sensitivity analysis}

Considering the aforementioned procedure, the proposed MPMP production planning problem can be solved as follows. First, fuzzy Eqs. (4) and (6) are converted to crisp ones using Eqs. (16) and (17) with $\alpha=0.5$. Then, the initial optimum value of each objective function is obtained by solving single-objective LP problems. The results are $z_{1}=\$ 667,195$ and $z_{2}=90.4 \%$. Next, the degree of membership $f_{g}\left(Z_{g}\right), g=1,2$, for different values of objectives should be specified by DM, as listed in Table 4. Figs. 6 and 7 depict the corresponding shapes of two piecewise linear membership functions. 


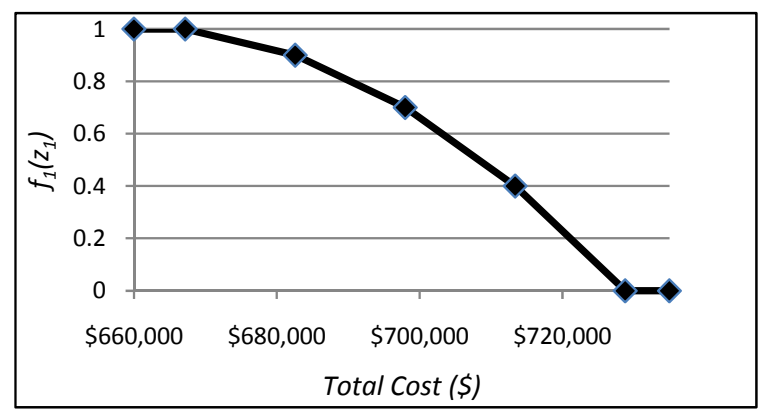

Fig. 6. Piecewise linear membership function $\left(z_{1}, f_{1}\left(z_{1}\right)\right)$

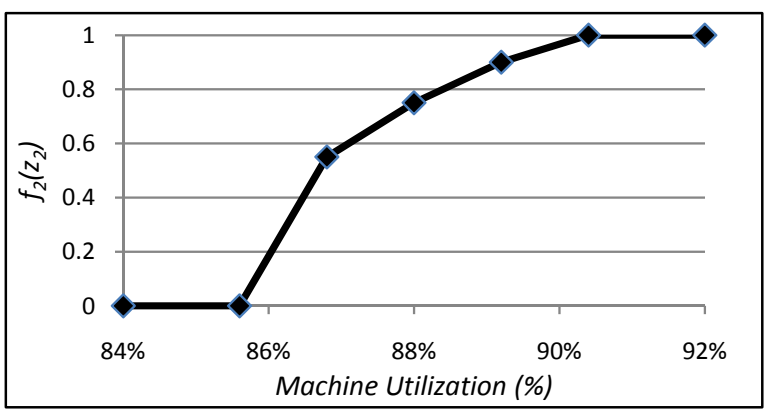

Fig. 7. Piecewise linear membership function $\left(z_{2}, f_{2}\left(z_{2}\right)\right)$

Table 5. Piecewise linear membership functions

\begin{tabular}{lccccccc}
\hline$z_{1}$ & $>\$ 728,802.6$ & $\$ 728,802.6$ & $\$ 713,400.7$ & $\$ 697,998.8$ & $\$ 682,596.9$ & $\$ 667,195$ & $\$ 667,195$ \\
$f_{1}\left(z_{1}\right)$ & 0 & 0 & 0.4 & 0.7 & 0.9 & 1.0 & 1.0 \\
$z_{2}$ & $<0.856$ & 0.856 & 0.868 & 0.88 & 0.892 & 0.904 & 0.904 \\
$f_{2}\left(z_{2}\right)$ & 0 & 0 & 0.55 & 0.75 & 0.9 & 1.0 & 1.0 \\
\hline
\end{tabular}

Consequently, by applying the auxiliary variable $\mu$, which specifies the total satisfaction rate of the DM, the multi-objective MPMP problem can be converted to a single-objective LP model. The complete LP model can be formulated as follows:

$\operatorname{Max} \mu$

$$
\begin{aligned}
& \text { s.t. } \mu \leq-3.24635 \times 10^{-6}\left(d_{11}^{-}+d_{11}^{+}\right)-3.24635 \times 10^{-6}\left(d_{12}^{-}+d_{12}^{+}\right)- \\
& 3.24635 \times 10^{-6}\left(d_{13}^{-}+d_{13}^{+}\right)-1.62318 \times 10^{-5} \times\left(z_{1}\right)+12.12975 \\
& \mu \leq-14.5833 \times\left(d_{21}^{-}+d_{21}^{+}\right)-2.0833 \times\left(d_{22}^{-}+d_{22}^{+}\right)- \\
& 2.0833 \times\left(d_{23}^{-}+d_{23}^{+}\right)+27.0833 \times\left(z_{2}\right)-22.8833 \\
& z_{1}+d_{11}^{-}-d_{11}^{+}=713400.7 \\
& z_{1}+d_{12}^{-}-d_{12}^{+}=697998.8 \\
& z_{1}+d_{13}^{-}-d_{13}^{+}=682596.9 \\
& z_{2}+d_{21}^{-}-d_{21}^{+}=0.868 \\
& z_{2}+d_{22}^{-}-d_{22}^{+}=0.88 \\
& z_{2}+d_{23}^{-}-d_{23}^{+}=0.892 \\
& \text { Eqs.(3),(4),(6-15), and (16), (17) }
\end{aligned}
$$

Where $d_{g e}^{+}$and $d_{g e}^{-}$denote the deviational variables at the eth point, $g=1,2, e=1,2,3$. Finally the crisp single objective LP model is solved with $\mathrm{LINGO}^{\circledR} 8.0$, and optimum values, $\mathrm{z}_{1}=\$ 681,850.06$, and $\mathrm{z}_{2}=88.37 \%$, were obtained. The overall satisfaction of the DM is equal to $90.05 \%$. By utilizing the proposed procedure, the DM can adjust parameters such as $w_{1}, w_{2}, w_{3}$, and $\alpha$ interactively to reach the most satisfactory result. Table 6 presents the optimal solution of the problem. For instance, 69 units of second product's first process is planned to be produced in first period and 51 units of its demand is planned to be subcontracted $\left(\mathrm{Q}_{2111}=69\right.$ and $\mathrm{Su}_{211}=51$ ). Thus, 120 units of second product continue their production sequence on second process $\left(Q_{2211}=120\right)$. Since machine center three is critical at first period and also considering the subcontracting price of each product, $\left(\mathrm{CSu}_{13}=400, \mathrm{CSu}_{23}=200\right.$, $\left.\mathrm{Csu}_{33}=400\right) 120$ units of product 2 are planned to be subcontracted $\left(\mathrm{Su}_{231}=120\right)$. Finally, 120 units of second product are planned to complete their forth process in the first period.

The proposed FMOLP model utilizes piecewise linear membership functions, presented by Hannan ${ }^{41}$, in order to deal with imprecise judgment of DM about objective values. In this respect, DM elicit satisfactory degrees for several objective values and the piecewise linear membership enable the DM to approximate satisfaction degree of intermediate points. In this approach, satisfactory degrees change with different rates according to different values of objectives. Hence, this method provides the DM with a flexible approach to embed his/her judgment in decision making process. Several methods of constructing membership functions have been suggested in literature (see Refs. 24, and 32 for more details). Table 7 demonstrates a comparison between adopting piecewise linear membership functions and linear ones. 
Table 6. Optimal solution obtained by solving the proposed FMOLP model

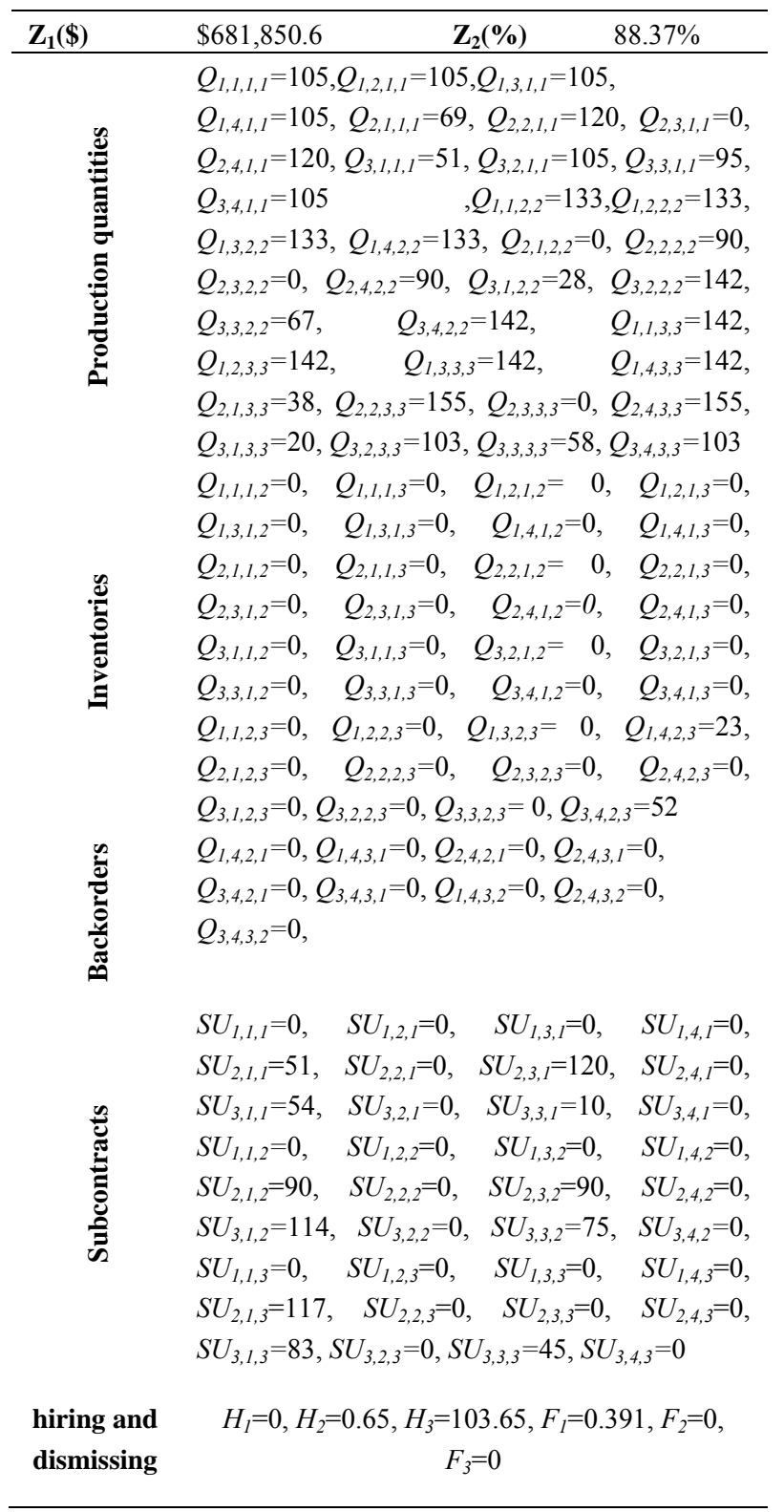

Table 8. Results of the sensitivity analysis in terms of changes in escalation factor

\begin{tabular}{llllll}
\hline Item & Run1 & Run2 & Run3 & Run4 & Run5 \\
\hline $\begin{array}{l}\text { Escalation } \\
\text { factor }\end{array}$ & $0 \%$ & $1 \%$ & $2 \%$ & $5 \%$ & $8 \%$ \\
$L$ & & & & & \\
$\mathrm{Z}_{1}(\$)$ & 668430 & 682833.8 & 697478.3 & 742685 & 789918 \\
$\mathrm{Z}_{2}(\%)$ & $87.8 \%$ & $87.5 \%$ & $87.3 \%$ & $86.7 \%$ & $86 \%$ \\
\hline
\end{tabular}

In real-world production planning problems, cost categories are normally affected by interest rate, thus the time impact of money should be taken into consideration in decision making process. In this respect, the first period is specified as a basis of calculations in case of considering time value impact of money. Table 8 represents trend of DM's overall satisfaction degree in regard with production costs and machine utilization and Fig. 8 demonstrates the trend. Although, production plan and machine utilization represent almost linear increasing and decreasing trend, overall satisfaction of DM decreases with a nonlinear pattern which is due to adoption of piecewise linear membership functions.

Table 9, compares features of current MPMP optimization models with the proposed model. In this respect, several significant features of the proposed model can be summarized as follows:

- The proposed model applies several practical strategies to absorb fluctuations of market demand over planning horizon.

- It also include more convenient general managerial decision making aspects of production planning such as issues related to labor levels.

- The impact of economical issues, as an important feature of today's unstable market situations, has been considered and formulated in the proposed model.

Table 7. Comparative analysis

\begin{tabular}{|c|c|c|c|c|}
\hline Item & LP-1 & LP-2 & Linear Membership Function $^{* *}$ & The proposed FMOLP \\
\hline Objective function & Min $z_{1}$ & $\operatorname{Min} \mathrm{z}_{2}$ & $\operatorname{Max} \mu$ & $\operatorname{Max} \mu$ \\
\hline$\mu$ & $100 \%$ & $100 \%$ & $88.8 \%$ & $90.48 \%$ \\
\hline $\mathrm{z}_{1}(\$)$ & $\$ 667,195^{*}$ & $\$ 728,802.6$ & $\$ 674,087.1$ & $\$ 681,850.6$ \\
\hline $\mathrm{z}_{2}(\%)$ & $85.6 \%$ & $90.4 \%{ }^{*}$ & $89.8 \%$ & $88.4 \%$ \\
\hline
\end{tabular}

*Obtained by solving single objective LP model

${ }^{* *}$ The interval values of linear membership functions $\mathrm{f}_{1}\left(\mathrm{z}_{1}\right)$ and $\mathrm{f}_{2}\left(\mathrm{z}_{2}\right)$ are $(667195,728802.6)$ and $(85.6,90.4)$, respectively 
Fig. 8. Sensitivity analyses on escalation variation

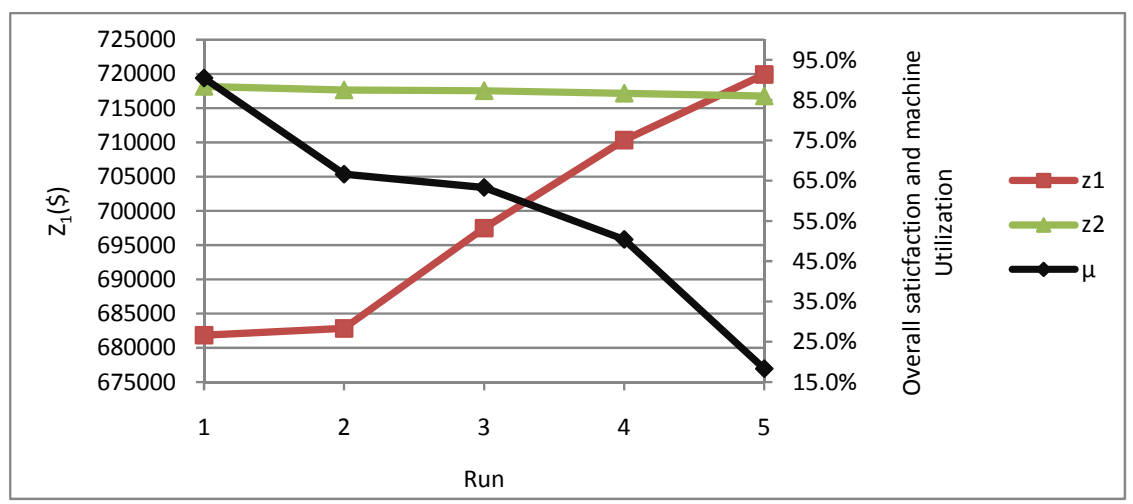

Table 9. Comparative analysis on features of different MPMP optimization

\begin{tabular}{|c|c|c|c|c|}
\hline Features & $\begin{array}{l}\text { Byrne \& Bakir } \\
\text { (1999) }\end{array}$ & $\begin{array}{l}\text { Jamalnia \& } \\
\text { Soukhakian (2008) }\end{array}$ & $\begin{array}{l}\text { Kazemi } \\
\text { Zanjani et al. } \\
(2009)\end{array}$ & Proposed model \\
\hline No. of product & Multiple & Multiple & Multiple & Multiple \\
\hline No. of period & Multiple & Multiple & Multiple & Multiple \\
\hline Production route & Not considered & Not considered & Not considered & Considered \\
\hline Subcontracting & Not considered & Considered & Not Considered & Considered \\
\hline Labor hiring & Not Allowed & Allowed & Not Considered & Allowed \\
\hline Labor layoff & Not Allowed & Allowed & Not Considered & Allowed \\
\hline Backorder & Not Allowed & Not Allowed & Allowed & Allowed \\
\hline \multicolumn{5}{|l|}{ Objectives } \\
\hline First objective & Cost & Cost & Cost & Net present value \\
\hline Additional & Not Considered & MIN: Labor Changes & Not Considered & Max: Machine Utilization \\
\hline objectives & & Costs \& Max: Customer & & \\
\hline & & Satisfaction & & \\
\hline
\end{tabular}

Table 10. Comparative analysis on different approaches of solving FMOLP

\begin{tabular}{ccccc}
\hline Method & Solution Type & $\begin{array}{c}\text { Number of sub- } \\
\text { problems }\end{array}$ & $\begin{array}{c}\text { Number of } \\
\text { additional Zero- } \\
\text { One variables }\end{array}$ & $\begin{array}{c}\text { Membership } \\
\text { function types }\end{array}$ \\
\hline $\begin{array}{c}\text { Piecewise linear } \\
\text { membership function } \\
\text { Yang et al. (1991) }\end{array}$ & Exact & - & - & Concave \\
Nakamura (1981) & Exact & - & $\sum_{i=l}^{n} v_{i}^{*}$ & Quasiconcave \\
Li and Yu (2000) & Approximate & $\sum^{2^{i-1}} v_{i}^{*}$ & - & Quasiconcave \\
\hline
\end{tabular}

${ }^{*} v_{i}$ represents the number of intersections between concave and convex functions. 
- Operational sequence or machine order visit has been considered in the proposed model to overcome fallacies of current MPMP optimization models.

Moreover, different approaches of solving FMOLP models are summarized and compared in table 10 .

Table 10 reveals that:

- The proposed solving method applies a convenient procedure to solve FMOLP models and provides an exact solution using a clear approach to express expert's judgments.

- The FMOLP model can be directly solved without additional zero-one variables or dividing the problem into sub-problems.

- However, the proposed approach can be only applied in case of concave membership functions.

\section{Conclusion, Remark, and further recommendations}

In practical applications of conventional MPMP model, the following issues should be taken into considerations:

1. The conventional MPMP models, normally, assume a same production route for all products, which leads to equal number of production volume at each process. This matter, consequently, may result in an unproductive utilization of machine capacity.

2. Conflicting objectives often exist in a shop floor considering different priorities and aspiration levels due to expert's judgments. There is, therefore, a need for optimizing such objectives through a simultaneous analyzing system.

3. Real world MPMP cases, generally, include ambiguous inputs or parameters due to lack of information or incomplete data.

Current study, initially, demonstrated the standard MPMP mathematical model may fail to utilize available capacity of machine centers. A novel MOLP model is thus developed considering individual production routes in order to simultaneously minimize present value of production costs and maximize machine utilization rate. Next, using piecewise linear membership functions and fuzzy minimum operator, aspiration levels of objectives have been aggregated throughout the proposed FMOLP model. Also, fuzzy triangular numbers were utilized to deal with fuzzy/imprecise parameters such as market demand and available machine capacity. Moreover, an interactive decision making procedure is then adopted to embed experts' judgments during the planning procedure. Finally, a numerical example was successfully implemented through the proposed FMOLP model and sensitivity analysis in case of considering the time value of money also presented.

Further studies can be focused on applying a control system after implementation of the proposed FMOLP model. Hereby, study on an integrated production planning-earned value management system, as a control mechanism, in such environment would be beneficial. The other potential future research may be carried out by applying stochastic modeling in case of the MPMP problem considering multi production routes.

\section{Acknowledgement}

The authors would like to acknowledge the anonymous reviewers for their constructive comments which have substantially improved the quality of paper over earlier versions.

\section{References}

1. F. Hanssmann and S. W. Hess, A linear programming approach to production and employment scheduling, Management Science. 2(1) (1960) 46-51.

2. M. Bakir and D. Byrne, Stochastic linear optimization of an MPMP production planning model, International Journal of Production Economics. 55(1) (1998) 87-96.

3. R. C. Wang and T. F. Liang, Application of fuzzy multiobjective linear programming to aggregate production planning, Computers and Industrial Engineering. 46(1) (2004) 17-41.

4. M. R. Feylizadeh, M. Modares and M. Bagherpour, Optimal crashing of multi period multi product production planning problems, World Applied Sciences journal. 4(4) (2008) 499-505.

5. D. W. Fogarty, T. R. Hoffmann and P. W. Stonebraker, Production and operations management (South-Western Publishing Co, Cincinnati, 1989).

6. L. J. Krajewski and L. P. Ritzman, Operations management: strategy and analysis (Addison-Wesley, Singapore, 1999). 
7. A. C. Hax and D. Candea, Production and inventory management (Prentice-Hall, Englewood Cliffs, 1984).

8. P. J. Billington, J. O. McClain and L. J. Thomas, Mathematical programming approches to capacity constrained MRP systems: Review, formulation and problem reduction, Management Science. 29(10) (1983) 1126-1141.

9. M. D. Byrne and M. A. Bakir, Production planning using a hybrid simulation-analytical approach, International Journal of Production Economics, 59(1) (1999) 305-311.

10. B. Kim and S. Kim, Extended model for a hybrid production planning approach, International Journal of Production Economics, 73(2) (2001) 165-173.

11. M. D. Byrne and M. M. Hossain, Production planning: An improved hybrid approach, International Journal of Production Economics, 93(94) (2005) 225-229.

12. P. Brandimarte, Multi-item capacitated lot-sizing with demand uncertainty, International Journal of Production Research, 44(15) (2006) 2997-3022.

13. S. Noori, M. Bagherpour, F. Zorriasatine, A. Makui and R. Parkin, A new project scheduling approach for improving multi-product multi-period production planning, Proceedings of the institution of mechanical Engineers; Part B-Journal of Engineering Manufacture, 222 (11) (2008) 1517-1527.

14. M. Bagherpour, A. Zareei, S. Noori, and M. Heydari, Designing a control mechanism using earned value analysis: an application to production environment, International Journal of Advanced Manufacturing Technology, 49(5-8) (2010) 419-429.

15. M. Kazemi Zanjani, M. Nourelfath and D. Ait-Kadi, A multi-stage stochastic programming approach for production planning with uncertainty in the quality of raw materials and research, International Journal of Production Research,48(15-16) (2010) 4701-47023.

16. M. Kazemi Zanjani, D. Ati-Kadi and M. Nourelfath, Robust production planning in a manufacturing environment with random yield: A Case in sawmill production planning, European Journal of Operational Research, 201(3) (2010) 882-891.

17. Y. J. Lai and C. L. Hwang, Fuzzy mathematical programming: methods and applications (Springer, Heidelberg, 1992).

18. Y. Shi and C. Haase, Optimal trade-offs of aggregate production planning with multiple objective and multicapacity demand levels, International Journal of Operations and Quantitative Management, 2(2) (1996) 127-143.
19. R. C. Wang and T. F. Liang, Aggregate production planning with multiple fuzzy goals, International Journal of Advanced Manufacturing Technology, 25(56) (2005) 589-597.

20. L. A. Zadeh, Fuzzy sets, Information and Control, 8(1) (1965) 338-353

21. R. E. Bellman and L. A. Zadeh, Decision-making in a fuzzy environment, Management Science, 17(4) (1970) 141-164.

22. R. C. Wang and H. H. Fang, Aggregate production planning with multiple objectives in a fuzzy environment, European Journal of Operational Research, 133(3) (2001) 521-536.

23. H. J. Zimmermann, Description and optimization of fuzzy systems, International Journal of General Systems, 2(4) (1976) 209-215.

24. H. J. Zimmermann, Fuzzy programming and linear programming with several objective functions, Fuzzy Sets and Systems, 1(1) (1978) 45-56.

25. D. B. Rinks, The performance of fuzzy algorithm models for aggregate planning and different cost structure (North-Holland, Amsterdam, 1982).

26. K. Nakamura, Some extensions of fuzzy linear programming, Fuzzy Sets and Systems, 14(3) (1984) 211229.

27. H. J. Zimmermann, Fuzzy set theory and its application (Kluwer, Boston, 1996).

28. T. Yang, J. P. Ignizio and H. J. kim, Fuzzy programming with nonlinear membership functions: Piecewise linear approximation, Fuzzy Sets and Systems, 41(1) (1991) 3953.

29. M. Gen, Y. Tsujimura and K. Ida, Method for solving multi objective aggregate production planning problem with fuzzy parameters, Computers and Industrial Engineering, 23(1-4) (1992) 117-120.

30. R. C. Wang and H. H. Fang, Aggregate production planning in a fuzzy environment, International Journal of Industrial engineering/Theory, Application, and Practice, 7(1) (2000) 5-14.

31. H. L. Li and C. H. Yu, A fuzzy multi objective program with quasiconcave membership functions and fuzzy coefficients, Fuzzy Sets and Systems, 109(1) (2000) 5981

32. R. C. Wang and T.F. Liang, Applying possibilistic linear programming to aggregate production planning, International Journal of Production Economics, 98(3) (2005) 328-341. 
33. W. Fengjie, L. Jie and Z. Guangquan, A new approximate algorithm for solving multiple objective linear programming problems with fuzzy parameters, Applied Mathematics and Computation, 174(1) (2006) 524-544.

34. A. Jamalnia and M. A. Soukhakian, A hybrid fuzzy goal programming approach with different goal priorities to aggregate production planning, Computers \& Industrial Engineering, 56(4) (2009) 1474-1486.

35. J. Tang, D. Wang and R. Y. K. Fung, Fuzzy formulation for multi-product aggregate production planning, Production Planning and Control, 11(7) (2000) 670-676.

36. G. Q. Zhang, Y. H. Wu, M. Remias and J. Lu, An afuzzy max order and solution of linear constrained fuzzy optimization problems, East-West Journal of Mathematics, Special Volume (2002) 84.

37. G. Q. Zhang, Y. H. Wu, M. Remias and J. Lu, Formulation of fuzzy linear programming problems as four-objective constrained optimization problems, Applied Mathematics and Computation, 39(2-3) (2003) 383-399.

38. O. Engin, C. Kahraman and M. K. Yilmaz, A new artificial immune system algorithm for multiobjective fuzzy flow shop problems, International Journal of computational intelligence systems, 2(3) (2009) 236-247.

39. T. F. Liang and H. W. Cheng, Application of fuzzy sets to manufacturing/distribution planning decisions with multi-product multi-time period in supply chains, Expert Systems with Applications, 36(2) (2009) 3367-3377.

40. T.F Liang, Fuzzy multi objective production/distribution planning decisions with multi-product and multi-time period in a supply chain, Computers \& Industrial Engineering, 55(3) (2008) 676-694.

41. E. L. Hannan, Linear programming with multiple fuzzy goals, Fuzzy Sets and Systems, 6(3) (1981) 235-248.

42. G. W. Hintz and H. J. Zimmermann, A method to control flexible manufacturing systems, European Journal of Operational Research, 41(3) (1989) 321-334.

43. D. F. Li, J. X. Nan and M. J. Zhag, A ranking method of triangular intuitionistic fuzzy numbers and application to decision making, International Journal of Computational Intelligence Systems, 3(5) (2010) 522541.

44. H. Rommelfanger, Fuzzy linear programming and applications, European Journal of Operational Research, 92(3) (1996) 512-527. 